\section{Lichen ruber planus und Hepatitis-Viren}

Eine Assoziation des Lichen ruber planus mit einer Virushepatitis wird seit längerer Zeit diskutiert. HBV oder HCV verursachen chronische Entzündungen und Veränderungen der Immunantwort. Dass zumindest einer dieser Viren die Hauterkrankung stimuliert, ist nach aktuellen Daten wahrscheinlich. $\mathrm{n}$ einer israelischen Studie werteten die Autoren die Datenbank der landesgrößten Krankenkasse aus. Sie verglichen 1.557 erwachsene Patienten mit Lichen ruber planus mit 3.115 nach Alter und Geschlecht gematchten Kontrollpersonen.

Wie erwartet, war die Prävalenz von Hepatitis C bei den Lichen-ruber-Fällen höher als in der Kontroll-Kohorte (1,9 vs. $0,4 \%, p<0,001)$ - wobei der Zusammenhang bei über 60-Jährigen, Frauen und Nichtrauchern noch deutlicher war. In der multivariaten Analyse ergab sich nach Berücksichtigung von Alter, Geschlecht, Raucher-Status und sozioökonomischen Daten eine Odds Ratio von 4,19 (bei 95\%-Konfidenzintervall: 2,21-7,93).
Hepatitis B dagegen kam bei Lichen ruber planus nur geringfügig häufiger als bei den Kontrollen vor; in der multivariaten Analyse war dieses Hepatitisvirus war nicht mit der mukokutanen Erkrankung assoziiert.

Damit bestätigt diese bevölkerungsbezogene Untersuchung mit einer sehr großen Fallzahl diverse frühere Studien. Offenbar wird die Assoziation mehr im Mittelmeerraum sowie in Japan gefunden, weniger in Nordamerika oder Nordeuropa, dies könnte auf genetische Faktoren zurückführen sein.

Fazit: Die gefundene Assoziation zwischen der Knötchenflechte und Hepatitis

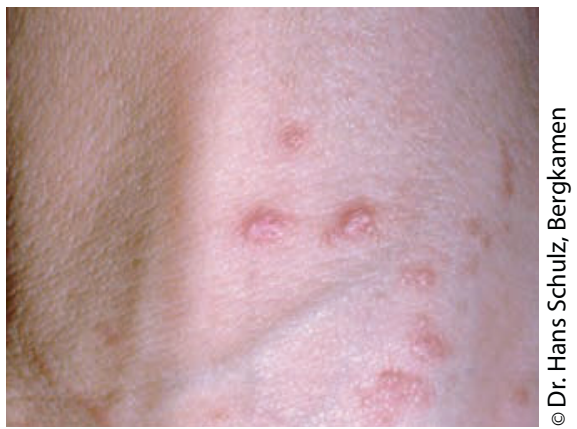

C ist ähnlich hoch wie schon in einer früheren Metaanalyse. Um eine Übertragung infektiösen Materials zu vermeiden empfehlen die Autoren - zumindest bei erosiven Formen oder bei Vorliegen weiScreening auf Hepatitis C.

Waldtraut Paukstadt

Birkenfeld $S$ et al. A study on the association with hepatitis B and hepatitis C in 1557 patients with lichen planus. J Eur Acad Dermatol Venereol 2011; 25: 436-40 terer Risikofaktoren - vorsorglich ein

\section{Papeln an Augenlidern, Lippen und Zunge}

Bei einem 16-jährigen Jungen fanden sich multiple Papeln und Knötchen an den Augenlidern, den Lippen und der Zunge. Sechs Jahre zuvor war bei seiner Mutter im Alter von 38 Jahren die Diagnose eines metastasierenden medullären Schilddrüsenkarzinoms gestellt worden.
Z um damaligen Zeitpunkt waren bei ihren beiden Söhnen deutlich erhöhte Kalzitoninwerte, allerdings kein laborchemischer Hinweis für ein Phäochromozytom, festgestellt worden. Bei beiden Jungen führte man daraufhin eine totale
Thyreoidektomie durch. Die sorgfältige pathologische Aufarbeitung der Schilddrüse dieses Jungen erbrachte ebenfalls ein medulläres Schilddrüsenkarzinom, allerdings nur in einem Durchmesser von $0,5 \times 0,5 \mathrm{~cm}$.

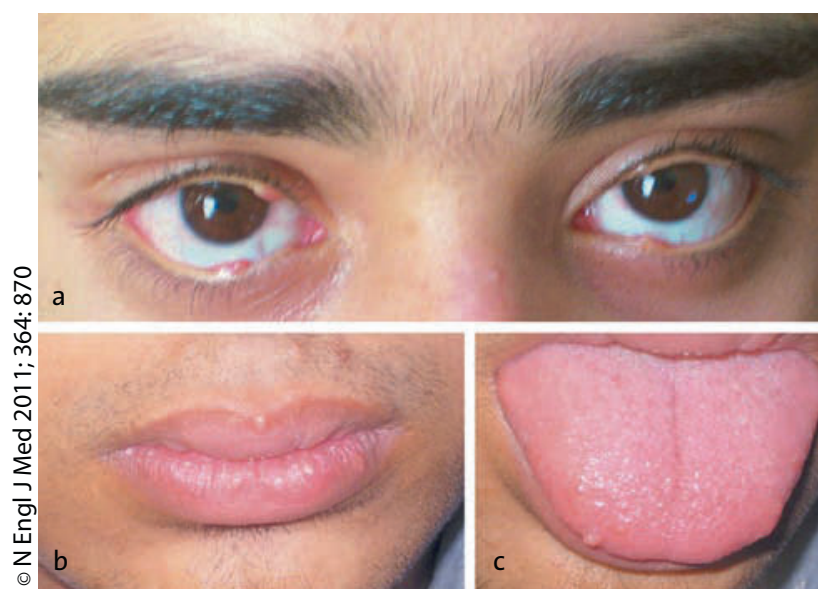

Papeln und Knötchen an Augenlidern, Lippen und Zunge des 16-jährigen Patienten.
Die Konstellation und die Anamnese der drei Personen sprechen für das Vorliegen einer multiplen endokrinen Neoplasie (MEN) Typ 2B, einer autosomaldominant vererbten Erkrankung, die durch ein medulläres Schilddrüsenkarzinom, ein Phäochromozytom, Schleimhautneurinome und einen marfanoiden Habitus gekennzeichnet ist.

Fazit: Zur Sicherung der Diagnose MEN ist heute eine Genotypisierung des RETProtoonkogens möglich. Diese ist bei den betroffenen Familienmitgliedern von großer Bedeutung für die genetische Beratung, ebenfalls wichtig ist ein Screening auf ein Phäochromozytom und die prophylaktische Thyreoidektomie. Der Junge erhält eine Substitution mit L-Thyroxin und unterzieht sich fortlaufend Screeninguntersuchungen. Diese auf den ersten Blick rätselhaften Befunde an Lidern, Lippen und Zunge erhalten einen ganz anderen Kontext, wenn man die Familienanamnese kennt. Prof. Dr. Hermann FüeßI

Tehrani MRM, Aalaa M. Papules on the eyelids, lips, and tongue. New Eng J Med 2011; 364: 870 